\title{
Papeles policiales: abuso de poder y eufemismo punitivo en la Policía Judicial de la ciudad de México
}

\author{
Elena Azaola Garrido y Miguel Ángel Ruiz Torres
}

Este trabajo se basa en el análisis de material etnográfico obtenido mediante la organización de grupos de discusión en los que participaron 166 agentes pertenecientes a todos los rangos de la Policía Judicial de la ciudad de México. Indaga en las prácticas de abusos de autoridad y de corrupción, las cuales han de comprenderse a partir de la necesidad de la reproducción institucional para conservar nichos laborales y estrategias de obtención de recursos. También considera el peso que tienen en dichas prácticas la precariedad en el trabajo y los abusos de poder que sufren los policías, forzándolos a instaurar códigos morales propios y reglas de conducta que a menudo generan, a su vez, abusos hacia la sociedad civil. Finalmente, analiza el uso de eufemismos legales que se convierten en coartadas de dominación derivadas de la legitimidad del Estado.

PALABRAS CLAVE: policía, abuso de poder, corrupción, impunidad, lenguaje eufemístico

Police Roles: Power Abuse and Punitive Euphemism in the Policía Judicial de la Ciudad de México (Mexico City Judicial Police)

This study is based on ethnographic material analysis, obtained through the implementation of discussion groups, in which 166 police officers, belonging to all ranks of the Policía Judicial de la ciudad de México (Mexico City Judicial Police), participated. It inquires into abuse of authority and corruption practices that have to be understood considering the need of institutional reproduction to conserve labor niches and resource acquisition strategies. It also considers the role of such practices on precarious employment conditions and power abuse suffered by police officers, forcing them to establish particular moral codes and behavior rules that, in their turn, frequently generate abuses towards civil society. Finally, it analyzes the use of legal euphemisms that are transformed into domination alibis derived from the State's legitimacy.

KEYWORDS: police, power abuse, corruption, impunity, State, institutional violence, euphemistic language

ELENA AZAOLA GARRIDO: Centro de Investigaciones y Estudios Superiores en Antropología Social-Distrito Federal, México eazaola@ciesas.edu.mx

Miguel ÁNGel Ruiz ToRres: Universidad de Valencia, España quelantor@yahoo.es

Desacatos, núm. 33, mayo-agosto 2010, pp. 95-110

Recepción: 11 de noviembre de 2008 / Aceptación: 20 de mayo de 2009 
Somos investigadores de papel, es decir, a base de puros informes y de mentiras se lleva a cabo todo. Agente veterano de la Policía Judicial del D. F.

\section{CORRUPCIÓNY ABUSO DE PODER}

U no de los pocos temas en los que hay consenso en todos los sectores sociales de México es el de la existencia de corrupción tanto en las fuerzas policiales como entre otros funcionarios y servidores públicos. El presente estudio propone un análisis de las prácticas de corrupción de los agentes de la Policía Judicial del Distrito Federal. Para llevarlo a cabo, hemos intentado trascender los límites que habitualmente se imponen las investigaciones al respecto, que tratan de identificar los patrones y la frecuencia de los abusos de poder, y hemos esbozado una metodología que parte de la información obtenida a partir de los propios agentes, con la finalidad de comprender el papel de dichas prácticas en el mismo contexto donde adquieren significado. Con base en la téclas opiniones y experiencias de los propios elementos y mandos de la Policía Judicial acerca de los temas que más les afectan en el desarrollo de su trabajo ${ }^{1}$. Nuestras preguntas fueron las siguientes: ¿Qué lugar ocupan las prácticas de corrupción y abuso de poder en el funcionamiento institucional de la procuración de justicia en la ciudad de México? ¿Se trata de fuerzas entrópicas que minan al Estado a la par que dañan gravemente la convivencia social? ¿Pueden estas prácticas llegar a tener alguna función estructural dentro de la reproducción institucional?

\footnotetext{
${ }^{1}$ Se organizó un total de trece Grupos de discusión (citados en el texto como GD 01 a GD 13) integrados por doce policías cada uno, con un total de 166 policías entrevistados pertenecientes a todos los niveles jerárquicos que existen en la Policía Judicial. Cada grupo estaba constituido por miembros de una misma jerarquía y generación, ello con el propósito de conseguir la mayor homogeneidad posible y tratar de evitar distorsiones en las opiniones por causa de obediencia al mando. Las entrevistas tuvieron una duración media de tres horas y se realizaron entre 2004 y 2005 en el Instituto de Formación Policial de la Procuraduría General de Justicia del Distrito Federal.
}

Aunque el concepto de corrupción alude, como se sabe, al abuso del poder público para obtener beneficios privados, ello no implica que los únicos susceptibles de ser corruptos sean los funcionarios públicos deshonestos. De hecho, la corrupción comprende prácticas en el sector público ( $v$. nepotismo y uso de información privilegiada), en la relación entre el sector público y el privado ( $v$. soborno y extorsión) y en el sector privado ( $v$. fraude y tráfico de influencias).

La corrupción ocurre en todos los países, sin importar su sistema político o económico. Sin embargo, tiende a proliferar en aquellos cuyas instituciones son débiles. Esto es, crece en lugares con sistemas legales ambiguos que se aplican discrecionalmente y en los que prevalecen las relaciones clientelares sobre las reglas formales. También donde las normas culturales son incompatibles con las leyes vigentes y donde ni los gobiernos ni las empresas rinden cuentas a sus ciudadanos y accionistas.

Existen en México, desde hace algunos años, diversas instancias de control de la actuación de los funcionarios, tanto de carácter institucional — que desempeñan funciones de control interno (contralorías, visitadurías y fiscalías) — como entidades independientes del gobierno que someten a escrutinio la labor de las fuerzas públicas (organizaciones de la sociedad civil y comisiones de derechos humanos). Teniendo en cuenta los datos más recientes, es evidente que la existencia de estos órganos no ha provocado una mejora en la actuación de los servidores públicos y, por consiguiente, no ha logrado garantizar una rendición de cuentas efectiva (Amnistía Internacional, 2004) debido a la negligencia y el corporativismo de los controles intrainstitucionales, así como al limitado despliegue de las agencias externas, en algunos casos, o su escasa capacidad para ser escuchadas, en otros.

La corrupción y el abuso de autoridad son prácticas de intercambio social en las que se ejecuta una conducta basada en una relación de poder, jerarquizada y desigual. Generalmente, los estudios sobre la policía se focalizan más sobre la llamada corrupción operativa, aquella que es producto de las relaciones con el medio externo a la institución, en el contacto cotidiano de los policías con los ciudadanos (Méndez, 2002). La otra corrupción, la que 
se conoce como corrupción administrativa, se da durante la gestión de los recursos humanos y materiales al interior de la institución, es decir, forma parte de la cultura institucional, y en el caso de la policía el tema ha sido abordado en pocas ocasiones (Azaola, 2006; Buckner, Christie y Fatth, 1983). Consideramos necesario el análisis de ambos tipos de corrupción porque, aunque es la primera la que causa mayor impacto en la ciudadanía, al disminuir la confianza en la policía e incrementarse la percepción de inseguridad, la corrupción intrainstitucional es considerada por los propios agentes, junto con la escasez de recursos, la principal causa de su falta de operatividad y de las conductas ilícitas en las que incurren.

Un problema implícito a la hora de definir la corrupción es su carácter relativo: para que una práctica sea considerada corrupta es necesario que alguien la juzgue como tal. No obstante, nosotros creemos que es posible definir estas prácticas si se sitúan en relación con la regulación del Estado. Por consiguiente, los principales rasgos de las prácticas corruptas son: a) implican a más de una persona; b) involucran, por lo menos, a un servidor público que se sirve de la autoridad de su cargo o función; c) conllevan un elemento de don u obligación mutua, en forma de retribución económica, bienes o servicios; d) se llevan a cabo de manera discreta u oculta; e) se necesita un marco legal desde el cual camuflar o justificar los actos ilícitos, o coaccionar para su ejecución; f) no pueden nunca ser legitimadas de forma pública, pero sí de manera informal; g) se reproducen a sí mismas, es decir, son altamente contagiosas: la corrupción produce más corrupción.

Según la evidencia recogida en denuncias, recomendaciones, encuestas y estudios de campo, los funcionarios de la Policía Judicial del Distrito Federal, durante el desempeño de su trabajo, violan habitualmente derechos civiles y políticos de los ciudadanos al cometer irregularidades, abusos de poder y actos de maltrato (Naval, 2006: 6) —aunque hay que señalar que son mucho más frecuentes los actos menos graves-. Así, según la Comisión de Derechos Humanos del Distrito Federal, que ha expedido varias decenas de Recomendaciones dirigidas a la Procuraduría General de Justicia del Distrito Federal desde el año 1994, las denuncias conciernen a la detención arbitraria; la dis-

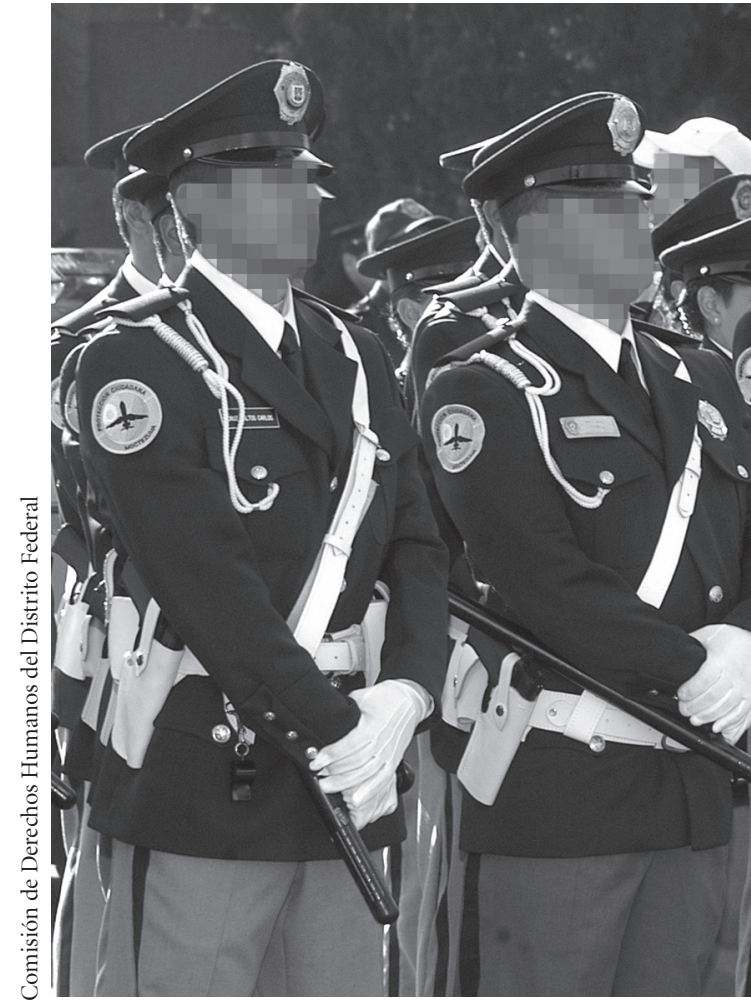

Cadetes, 2005

criminación; la inculpación ilegal; la violación al derecho a la integridad física, la dignidad, el honor y la libertad personal; el trato cruel, degradante e inhumano; y las injerencias arbitrarias en el interés superior del niño (véanse CDHDF, 2005, 2006, 2007a).

Según se desprende de una Recomendación (CDHDF, 2007b), para los servidores públicos sus actuaciones se basan en los siguientes supuestos y criterios: a) la presunción de culpabilidad; b) la criminalización de sujetos y no de conductas; c) la arbitrariedad procesal; d) la carencia de derechos para acusados y sospechosos; e) la prueba de no haber participado en un delito recae en el acusado y no en la obligación de la Fiscalía de investigar los hechos; f) la "puesta a disposición" no es preventiva, es discrecional y arbitraria, y depende más del funcionamiento interno de la institución que de la existencia o no de un delito; g) la aplicación ad hoc del Código Penal, es decir, se crea (fabrica) una figura de delito adecuada para el caso; h) la mera 


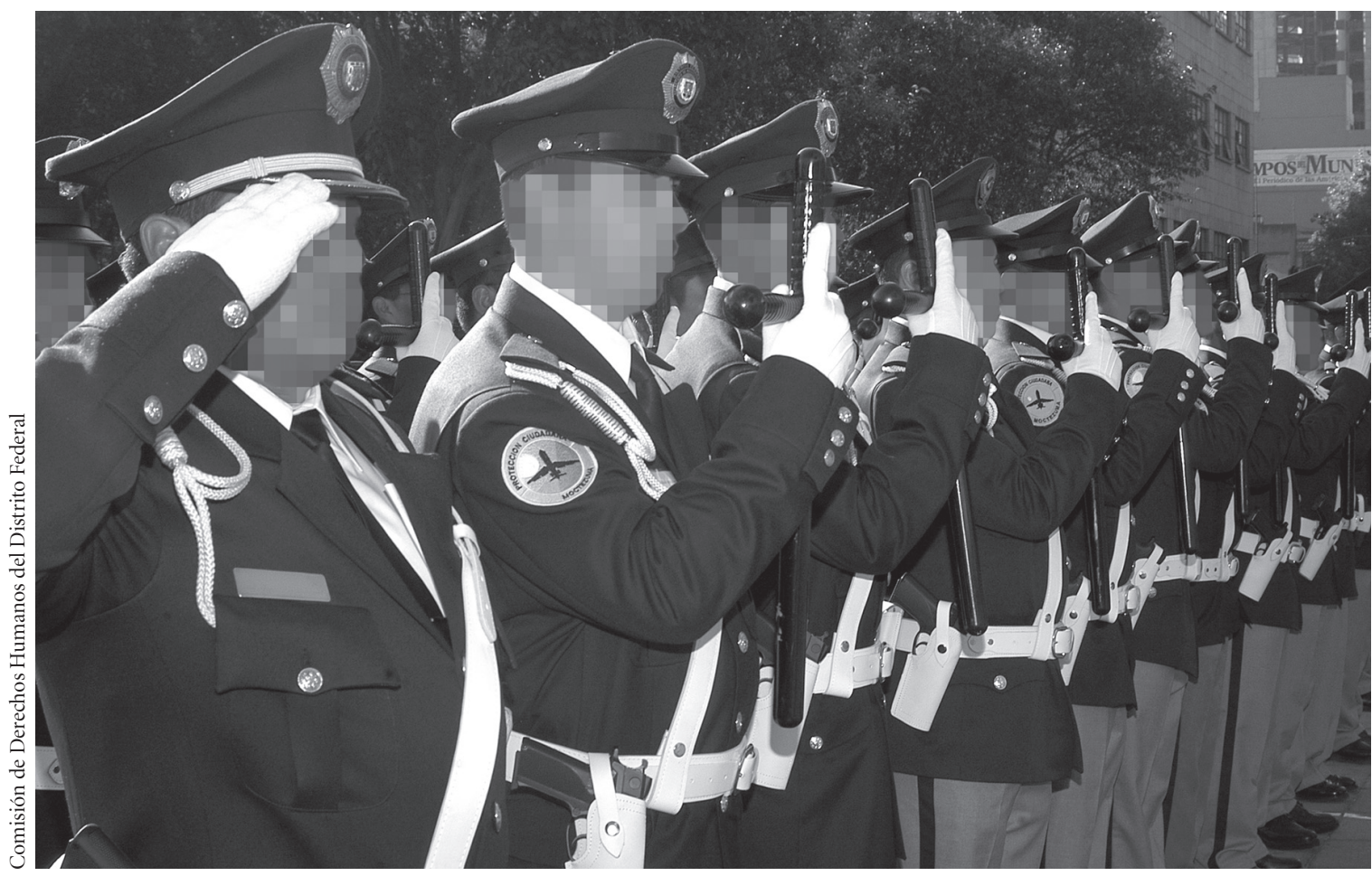

La lealtad y la obediencia son rasgos importantes de la cultura institucional, 2005.

"puesta a disposición" convierte de facto en culpable al presunto delincuente, por lo cual el potencial para extorsionar se deriva de esta retórica legal, que se convierte en un eufemismo como coartada para el abuso de poder.

Por otro lado, es importante hacer hincapié en el hecho de que los policías judiciales también sufren violaciones a los derechos humanos. La mayor parte de éstas es consecuencia de las condiciones precarias y deficientes en las que tienen que desempeñar su trabajo y la falta de respeto a su integridad, en especial a su honor y su salud psicofísica.

\section{ABUSO DE PODER: LA FALSA DISYUNTIVA ENTRE EFICIENCIAY LEGALIDAD}

El dilema entre el derecho y el orden está en el centro de todo debate sobre la democratización. Así, mientras que la legalidad consiste en hacer cumplir las leyes legalmente, el orden suele expresarse mediante la eficiencia con la que éste ha logrado imponerse (Matza, 1981: 233). Invocando la coartada de "lograr la eficacia en la persecución y el castigo de los delitos", la política criminal inflacionaria recurre a menudo a la violación de las garantías procesales que son fundamento de un Estado de derecho (Pastor, 2005: 74). En nuestro caso, el pulso entre el respeto a la ley y la eficiencia en los resultados cruza constantemente el discurso de los policías judiciales y justifica el uso de la violencia y el abuso de poder. Un coordinador nos confiesa, así, que solamente con medios ilegales es posible conseguir el fin del arresto: "la ley nos limita, no podemos parar un auto injustificadamente. Necesitamos 'armas' para poder detener, porque ahora sólo podemos cuentear a los sospechosos de que los detenemos para verificar esto o lo otro" (GD 02).

El mecanismo vigente de la averiguación previa, el cual permite recabar datos que puedan tener valor probatorio 
en el juicio, anima a la policía y a los agentes del Ministerio Público a fabricar pruebas para conseguir que se dicte la sentencia condenatoria (Amnistía Internacional, 2004). Así nos lo hace saber un comandante: "el MP nos dice 'no anotes que ya estuvo detenido, eso no te lo pedí. Lo que pasa es que nosotros podemos hacer 'cuadrar' el expediente según los datos que anotemos" (GD 06). Esto significa que los informes escritos que integran una averiguación previa, supuestamente basados en las declaraciones de los detenidos y en otros datos, son modificados para hacerlos coincidir (cuadrar) con la descripción del delito que contiene el Código Penal, lo cual permite iniciar una causa.

La validez de la confesión como prueba autoincriminatoria, aunada a la facultad de "custodiar" al detenido durante horas, hace que la coacción física, psicológica y/o moral, y la tortura, a pesar de no ser reconocidas por los policías, sean de hecho practicadas regularmente. Algunas declaraciones nos dejan entrever que estos actos son utilizados y racionalizados usualmente. Un comandante dice: "el MP agarra el Código Penal para desafanar a los delincuentes porque ellos son los que ordenan, pero uno también puede ver el código. Por eso, cuando yo presento a los delincuentes, ya los presento bien quebrados" (GD 06). En general, el uso de la violencia contra los individuos criminalizables es justificado por los policías como una necesidad de la labor policial, en un mundo moral maniqueo dividido entre ellos y los enemigos (el resto de la sociedad): "estamos trabajando en la calle y eso significa que tenemos que golpear gente porque así es la calle, la gente es mala" (GD 11).

\section{POLICÍAS JUDICIALES: ¿EJECUTORES O CREADORES DE LA VIOLENCIA INSTITUCIONAL?}

Cuando los policías judiciales incurren en prácticas de abuso de poder y delitos contra los ciudadanos, iconstituyen unos meros instrumentos de la represión del Estado a través del sistema jurídico-penal?, ¿o son ellos los únicos responsables, a título individual o grupal, de las conductas corruptas? El panorama se esclarece un poco si tenemos en cuenta que los policías forman parte de la sociedad general pero, al mismo tiempo, conforman una sociedad (de pequeña escala) con sus propias normas que, debido a sus rasgos de lealtad y corpus moral común, llamaremos clan².

Así pues, los policías judiciales están integrados en clanes informales internos dentro de los grupos formales, a los que deben obediencia y reciprocidad, y en los cuales el contexto es de mayor confianza. Éstos están compuestos por los agentes que habitualmente colaboran juntos en tareas de patrullaje e investigación bajo las órdenes de un mismo jefe, aunque no es necesario que el liderazgo moral de éste sea reconocido, al contrario, parece que la solidaridad grupal se consolida al confrontar las exigencias y arbitrariedades de la jerarquía.

La formación del sentido del clan es relativamente espontánea y no necesita de planificación estratégica; se origina en un doble movimiento que crea una red de apoyo mutuo: por una parte, es una reacción defensiva frente a la desconfianza generalizada y las amenazas externas (a la integridad física, a la continuidad en el trabajo, a las acusaciones diversas) y, por otra, es una manera de garantizar que los recursos de todo tipo que consigue la lógica de la corrupción continúen llegando para permitir la supervivencia del nicho laboral. Fuera del clan, un policía judicial es reconocido por los otros como alguien con quien se puede hablar el mismo idioma, pero no como un compañero, es decir, aquel con quien se está moralmente obligado por reciprocidad. Así se explica por qué las relaciones con otros funcionarios, como los agentes del Ministerio Público, son tan problemáticas: aunque administrativamente están supeditados a ellos, el mando policial paralelo los convierte en iguales con los que uno se entiende hasta cierto punto, pero con quienes se compite por el mismo recurso.

Una vez que se pertenece a un clan, hay que cumplir las normas para no ser excluido, por lo que las conductas poco claras o el compromiso ambiguo son mal tolerados

\footnotetext{
${ }^{2}$ Podría intercambiarse el término clan por el de red social, pero preferimos usar el primero para enfatizar la existencia de un interés común que crea obligaciones.
} 
y censurados. Pertenecer al clan significa asumir un código moral que le es propio, no excluyente ni incompatible, pero sí paralelo al de la sociedad en general. La necesidad de un estrecho corporativismo, así como la adopción de una ética con fuertes connotaciones proteccionistas, enraiza en la definición social negativa que les genera a los sujetos el estigma de ser un policía judicial.

Como el clan es informal y dinámico, su existencia se puede deducir de las conductas y las representaciones del mundo social que se hacen los policías, aunque no sea explícitamente reconocido por ellos. Por ejemplo, la presencia del clan se evidencia en esta queja de un agente ante el reparto de beneficios fuera del mismo: "nosotros agarramos a una banda muy pesada y nos dieron un estímulo pero se repartió entre muchos que no hicieron nada" (GD 07). El reconocimiento de la operatividad de los clanes corporativos más reducidos se puede observar en la propuesta de este agente: "la policía debería hacer equipos, no grupos, aquí la verdad es que hacemos las cosas como podemos" (GD 11).

La falta de libertad de expresión y de la posibilidad de asociarse formalmente para plantear sus demandas laborales también es un factor de cristalización del clan informal mediante el cual sus miembros logran crear un entorno protegido. Pero el enfrentamiento con el poder jerárquico, especialmente con los mandos directos, es uno de los principales factores aglutinantes de intereses. Así, aquellos policías que llevan a cabo acciones egoístas son considerados desleales: "no hay compañerismo entre nosotros porque luego unos hacen una puesta a disposición. Siempre hay alguien que está dispuesto a quedar bien con el jefe porque tiene necesidad de descansar el domingo" (GD 09).

Hemos encontrado numerosos lamentos de los policías respecto de la falta de unidad para defender los intereses comunes. Pero esto, lejos de significar que las redes de apoyo no existen entre ellos, evidencia que éstas son más difíciles de estabilizar por la propia movilidad del espacio de trabajo y las condiciones peligrosas del medio donde se desenvuelven. Es decir, que los policías necesitan, más que otros funcionarios, un ámbito de protección altamente restringido y eficaz cuya reciprocidad es vital para la supervivencia, de ahí los continuos reclamos de fidelidad en su entorno social. Se trata, de nuevo, de reducir al máximo posible la desconfianza en su órbita más cercana de trabajo. En este sentido, es importante tener en cuenta que la percepción de que los demás funcionarios están más organizados en clanes de intereses que uno mismo es precisamente un síntoma de la necesidad de formarlos, y también de que se conoce la efectividad de esta práctica: "los MP se hacen el paro unos a otros, se protegen mutuamente, se encubren; nosotros no" (GD 12). Una lectura complementaria de esta percepción de desunión es que los clanes son espacios muy dinámicos e inestables, donde constantemente entran y salen miembros, y donde proliferan las situaciones sociales de competencia por el estatus frente a la jerarquía.

Pero las expresiones de lealtad al clan son también frecuentes. Esta fidelidad normalmente se da de manera horizontal en relaciones entre iguales, y puede llegar a tal grado que es capaz de satisfacer más las necesidades afectivas que los propios ámbitos familiares íntimos. Un agente nos confiesa que "emocionalmente nos sentimos más cerca de nuestra pareja [policía] que de nuestra familia" (GD 12). En este sentido, la gran capacidad que tiene el trabajo de policía de colonizar las diversas vivencias (Gadamer, 2005: 102) de los sujetos, hace que su mundo de la vida pueda resultar difícilmente comprensible para aquellos no pertenecientes al clan, o como mínimo a la cultura policial, a quienes les son ajenas e incluso hostiles las acciones racionalizadas y la regulación normativa y moral que éste conlleva.

En ocasiones, la obediencia y la lealtad a la jerarquía del clan es mitificada mediante el simbolismo de la comunión (Cohen, 1974: 32) con el fin de lograr la ansiada fidelización del entorno. La exigencia de una obediencia ciega a la jerarquía es reivindicada por la mayoría de los mandos. Por ejemplo, un coordinador afirma: "el mando es el mando, yo ordeno a mis elementos y se acabó, no tiene por qué haber comunicación" (GD 03). Este acatamiento puede proporcionar ventajas para el ascenso jerárquico, aunque no implica un reconocimiento de la autoridad del mando, sino una escenificación de obediencia: "Me encargaron de jefe teniendo sólo nueve meses de haber ingresado, me dejaron el mando y es que yo no peleo con ellos, yo les cuento que fui mariachi" (GD 10). 
No obstante, cuando en un clan se da la desobediencia al mando, hay más condescendencia por parte de unos jefes que también están obligados a reciprocidad con sus subalternos, por lo que opera una redistribución de premios y castigos. Un agente nos cuenta que "ya como policía uno ve las represalias de los mandos, porque si uno no es de su grupo, te arrestan. Te dan amonestaciones, que porque no hicimos las órdenes" (GD 12). La existencia de relaciones de lealtad, horizontales y verticales, al interior de cada clan, es garantizada por el interés en prolongar y reproducir un entorno fidelizado, lo cual conlleva el traslado de todo el clan junto con su mando: "cada quien llega con su gente, aunque no esté preparada. Uno puede estar trabajando bien pero luego llegan los nuevos recomendados y desbaratan todo" (GD 09).

Por la frecuencia y facilidad con que son generadas las situaciones de abuso de poder, los miembros del clan son muy susceptibles de percibir traiciones de la lealtad debida por parte de los jefes, por lo que los clanes incorporan reciprocidades verticales que están cruzadas de conspiraciones horizontales e incluso individuales. Otra percepción frecuente de traición al corpus moral se da con los ascensos, abrumadoramente percibidos como injustos por parte de los agentes, y originados en tráfico de influencias. Un policía veterano ve en ello la causa del abuso de poder que sufren: "el jefe general no es policía, él era de papeles, de archivo, y han brincado a jefes sin méritos y así se dan el lujo de arrestar a compañeros" (GD 07).

Las normas morales y de conducta que se ejercen en la cultura policial, específicamente al interior de un clan, no son necesariamente incompatibles con las de la sociedad en general, pero es frecuente que en un conflicto entre ambas predominen las primeras. La moral del clan implica la lógica de una justicia propia hecha a la medida de y para la reproducción del grupo. Este lamento de un comandante hace vincular la identidad del policía judicial con la existencia de este corpus moral: "aquí ya no hay lealtad entre los policías, antes teníamos un código de honor 'perro no come perro', pero ya se acabó eso, no hay reglas de honor" (GD 04).

La reproducción de las prácticas policiales requiere un aprendizaje y una iniciación en el corpus moral propio por parte de los nuevos agentes, especialmente en lo que se refiere al ejercicio y la tolerancia del poder arbitrario. En otras palabras, con el ingreso en un clan policial el individuo inicia una "carrera moral" (Goffman, 1993: 46) a partir de la interiorización de las normas de conducta heredadas y reproducidas por sus predecesores de otras generaciones. El requisito de que los nuevos actores presenten poca resistencia a dicha socialización, con el fin de garantizar la reproducción normativa, está en el origen de las continuas quejas que hemos encontrado en los mandos referentes a la "necesidad de vocación" de los novatos: "hay gente que será abogado pero no tiene vocación de policía, no tiene el amor a la profesión" (GD 02). Deducimos que por "vocación" ha de entenderse aquí una mayor docilidad a la hora de aceptar la jerarquía (tanto formal como por antigüedad) y las normas del clan. Es decir, la vocación policial se contrapone a la formación académica porque con esta última los novatos obtienen más conocimiento de la legalidad y de sus derechos como trabajadores, los cuales frecuentemente se contraponen al funcionamiento real del clan, que reproduce los nichos laborales pero a cambio de un abuso de poder intrainstitucional constante. Un alto mando recalca el peligro potencial que encarna toda formación: "nos deberían consultar a los mandos lo que se debería enseñar en esos cursos, con base en nuestra experiencia nosotros deberíamos aprobar lo que se les enseña a los jóvenes que ingresan" (GD 01).

La irrupción de un ethos diferente, mediante la formación académica, dificulta la cristalización de una solidaridad de clan que encubra las prácticas corruptas "tradicionales", por lo que los mandos insisten en la necesidad de un regreso a la iniciación informal: "Nosotros pensamos que los nuevos deben ser preparados por policías, no por académicos" (GD 03). Las generaciones provenientes de la academia son vistas por los mandos como amenazantes porque, al poner en cuestión las reglas no escritas de la reproducción institucional, desestabilizan el constructo de obligaciones, las cuales subyacen a todo abuso de poder: "tenemos que hacer coperachas por accidentes o por caución que le piden a algún compañero. Cooperamos para arreglar las patrullas. Luego resulta que nos denuncian los elementos por pedirles dinero para patrullar" (GD 03). También un agente nos habla del co- 
lapso que la formación está produciendo en la lealtad al clan: "yo también cuando entré, así era, y agradezco a las personas que así me enseñaron. Sin embargo, ahora los nuevos elementos entran cuidándose de la gente que es vieja, y eso es lo peor, porque lo único que les enseñan es cómo romperle la madre a su compañero" (GD 11). En definitiva, las fracturas generacionales, racionalizadas en el discurso por la falta de destreza de los nuevos agentes, crean más incertidumbre, desconfianza y, por consiguiente, inseguridad; es decir, resquebrajan el entorno protegido que tanto esfuerzo le ha costado construir al clan.

Pero, ¿qué papel juegan los policías judiciales y qué responsabilidad tienen en la reproducción de la violencia institucional? En primer lugar, cabe subrayar que la corrupción y la violencia policiales no dejan de ser, desde el punto de vista del corpus moral del clan, conductas racionales con fines instrumentales, y no fines en sí mismas. Esta constatación, aunque debilita las tesis psicologistas acerca del supuesto sadismo de los agentes, conduce también a una afirmación del cinismo moral en la práctica policial. Es decir, ciertas conductas violatorias de los derechos humanos dejan de ejecutarse debido a que ya no son eficaces en el contexto neopunitivista y no porque atenten contra la dignidad de las personas. Por ejemplo, un coordinador veterano explica cómo la tortura se ha convertido en una práctica poco eficaz para los policías: "la tortura ya no existe porque anteriormente valía la confesión como prueba, ahora ya no hay necesidad ni uno se arriesga. El obtener yo una confesión de nada va a servir en un juzgado ni en el Ministerio Público" (GD 02). Según esta lógica, al ejercer la violencia, los policías actúan correctamente en el horizonte ético de la defensa de su nicho laboral. En este sentido, el objetivo de la mayor parte de las conductas de abuso de poder parece ser la reducción de la incertidumbre y el aumento de la seguridad de los miembros de cada clan.

La violencia policial es justificada por sus ejecutores como autodefensa frente a las agresiones y como necesaria en su cometido de aplicación de la ley. Pero, en realidad, tal violencia es un componente estructural dirigido a garantizar la reproducción institucional. Esta necesidad creciente de imposición coercitiva de las normas del clan

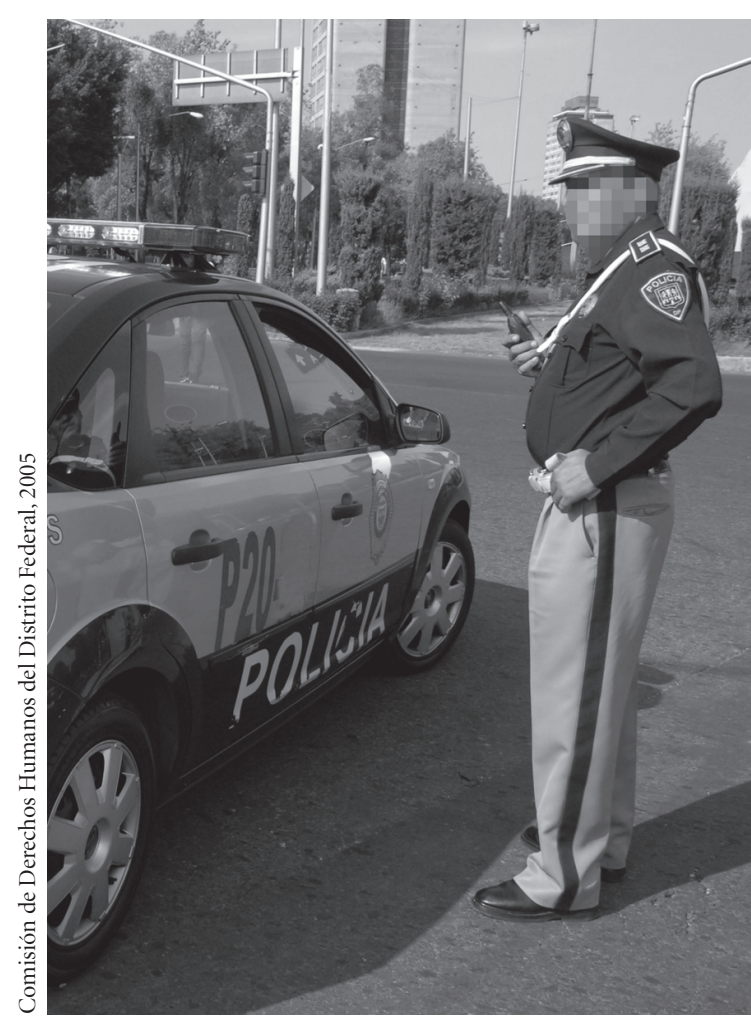

Vigilante, 2008

hacia el exterior del mismo es una consecuencia del aumento, registrado en los últimos años, de territorios situados fuera del contrato social, considerados tierra de nadie con normas locales autónomas basadas en la violencia y el terror (Davis, 2006: 82). Estas geografías paraestatales que los policías deben recorrer durante su trabajo, peligrosas, micropolíticamente densas y regidas por hombres fuertes y grupos criminales, han generado una reacción defensiva de los clanes policiales que se expresa en una cada vez menor capacidad y motivación para intervenir, una mayor negligencia en la acción policial y una poderosa introducción de la lógica de laissez faire en los códigos morales propios para permitir la supervivencia. En pocas palabras, a territorios con normas locales fuera del Estado de derecho, la policía responde con más normas locales limitadas al horizonte moral del clan y de sus socios externos, y con la mínima pretensión de garantizar la propia supervivencia. 
Aparentemente, se trata de dos paralegalidades en lucha y en negociación, confrontación en la cual el sistema jurídico-penal actúa como los ases en la manga (con trampa) de una de las partes: la que tiene formalmente el derecho otorgado por el Estado de aplicar la legalidad institucional mediante el uso de la coerción. No obstante, el mayor control de la arbitrariedad policial, el aumento de la transparencia mediática y la no menos influyente acción del neopunitivismo intrainstitucional han generado un debilitamiento en la capacidad de los clanes de imponer sus normas contra la sociedad. Ésta es la razón por la cual nos hemos encontrado en los grupos de discusión recurrentes expresiones de añoranza de tiempos pasados en los que la policía detentaba un mayor poder arbitrario para ejercer la violencia. Este agente veterano se lamenta lacónicamente de que: "antes se podía trabajar con orden y sin orden de aprehensión, pero ahora no, por eso el delincuente se burla de nosotros, están arriba de nosotros" (GD 07).

\section{EL LENGUAJE EUFEMÍSTICO COMO COARTADA DEL ABUSO DE PODER}

Un eufemismo es, etimológicamente hablando, una palabra que suena bien ${ }^{3}$; de ahí que se le defina como aquella estrategia discursiva que, mediante el empleo de otras figuras retóricas, sustituye una expresión dura, vulgar o grosera por otra suave, elegante o decorosa (Beristáin, 2001: 202). Su finalidad es variada, aunque su uso es muy frecuente en el lenguaje político y diplomático. Pero, ¿por qué se emplean eufemismos en el abuso de poder?, ¿ por qué la función de dominación parece más eficaz si se comete en nombre de la "puesta a disposición" y no de lo que realmente suele ser un secuestro "legal"? Creemos que, mediante la referencia al eufemismo emanado del derecho, las resistencias a la violencia institucional son menguadas, aplacadas y disipadas, ya que ésta se aplica bajo la coartada de la legitimidad del Estado. Por consiguiente, la función simbólica de los eufemismos legales (mediante significados neutralizados, trasmutados o neologis-

\footnotetext{
${ }^{3}$ Del griego eu: bien, y phêtê: habla.
}

mos) es encubrir el horror de la violencia, y consiste en una práctica reiterada de apropiación del lenguaje institucional con fines del ejercicio de poder arbitrario. Veamos, en palabras de un coordinador, un ejemplo de utilización de terminología en un conflicto de poder intrainstitucional:

\begin{abstract}
Nosotros ya la pensamos muy bien antes de hacer una consignación o de salirnos de nuestra zona para hacer alguna investigación porque nos metemos en problemas. A unos compañeros les iniciaron una averiguación por robo de auto [la patrulla] cuando se salieron de su zona para ir a hacer una diligencia. La orden es que, antes de averiguar, consignen a todos los policías judiciales por cualquier irregularidad (GD 03).
\end{abstract}

Nos encontramos aquí con varios eufemismos interesantes. En primer lugar, una consignación, en este discurso, contiene latente la violencia del arresto arbitrario en la vía pública sin existencia de flagrancia o incluso en domicilios particulares sin orden judicial. Por su parte, una averiguación previa aquí nos aparece con una fuerte carga peyorativa, una práctica capaz de estigmatizar a los policías, y que es aplicada como represalia por una causa de orden interno, probablemente ajena a la acusación formal Por último, una irregularidad es un eufemismo más amplio que puede involucrar cualquier acto de corrupción y abuso de poder cometido por un servidor público. Cada uno de los términos es polisémico, contiene varias capas de significado contextual, estructural y situacional, una densidad de sentidos.

Debemos hacer énfasis en el efecto perverso que el uso del eufemismo posee en este contexto. Así, a mayor distancia entre el sentido original de un término legal y la práctica de abuso que genera, mayor es su eficacia. Por ejemplo, una puesta a disposición es, quizás, muchas cosas antes de poner al imputado a disposición de un juez (para protegerlo a él y prevenir la comisión del delito): es la creación de un ámbito de poder arbitrario que rodea al individuo y lo sustrae de su contexto social de obligaciones y derechos informales. Poner a disposición es sinónimo de imponer un código de poder que responde al cuerpo moral de los clanes. Se trata de ubicar al individuo a disposición de los significados que sobre él recaigan en 
virtud de que es un sujeto criminalizable; es decir, ponerlo a disposición de una interpretación de poder arbitraria.

Es importante también remarcar que la violencia institucional es ejercida de manera más eficaz cuanto más incomprensibles, opacos y desplazados (desvirtuados de su sentido original) se perciban los términos eufemísticos utilizados, no solamente para el resto de los ciudadanos, sino incluso para los propios policías que se apropian de ellos. Con esto se consigue el efecto de neutralizar o atenuar la oposición que podría generarse si la imposición se efectuara en términos cotidianos y comprensibles, con sentidos compartidos, en el lenguaje ordinario. Así, el hecho de que la jerga legal sea inentendible (y de que no se pretenda hacerla entendible) otorga a los policías un efecto de poder redoblado sobre los criminalizables: a mayor ininteligibilidad del lenguaje jurídico, mayor posibilidad de que éste sea instrumentalizado para el abuso de poder.

Estos dos procesos - la distancia entre el significado literal y el real de un término, y la percepción de su ininteligibilidad - actúan sinérgicamente para potenciar el mecanismo del lenguaje eufemístico como coartada para el abuso de poder. Como consecuencia de esto, en el juego de lenguaje que utilizan los policías entre ellos y en su interacción con la población, los criminalizables son excluidos de la creación de sentido de los propios términos que los definen, razón por la cual quedan en situación de máxima vulnerabilidad ante el abuso de poder: a menor participación en la definición de la situación punible, mayor debilidad sufren ante el lenguaje legal.

Como consecuencia de la capacidad que tiene el sistema jurídico-penal de destilar el lenguaje eufemístico cuando es sometido al calor del ejercicio del poder, la terminología formal acaba por sobreponerse a lo que dicen y hacen las personas. Son, entonces, los sujetos criminalizables (incluyendo a los propios policías) los que son forzados a ajustarse al formalismo del lenguaje eufemístico y, en última instancia, sus conductas son encajadas en los tipos penales. De ahí que cuadrar una investigación sea, en términos fenomenológicos, llevarla a cabo en realidad. Así se evidencia en este desliz de un agente: “¿Cómo vamos a cuadrar los delitos? Pues solamente sabiendo el código" (GD 10).

La preeminencia que se otorga al informe escrito en los procedimientos del sistema jurídico-penal, en cuyo itinerario de "papeles" los policías judiciales han de movilizar sus recursos, hace que todos los actores participantes en la práctica policial estén volcados en los constantes esfuerzos por arrojar sentido hacia la máquina burocrático-punitiva; ser, de alguna manera, creadores de la realidad que ésta prescribe. Pero dadas las condiciones de inepcia de la procuración de justicia y el funcionamiento paralegal y corrupto del mismo, un burocratismo basado en el abuso de poder se convierte en una camisa de fuerza impuesta a la sociedad. La consecuencia inmediata de este "fetichismo" del lenguaje legal que constituye todo eufemismo es que la terminología jurídico-penal sirve a la legitimación de la propia institución mediante la creación de los objetos necesarios para su reproducción en el mundo social.

\section{INVESTIGADORES DE PAPEL: UNA POLICÍA SIMULADAY ESCENIFICADA}

Reconocer la importancia del lenguaje eufemístico en la práctica policial implica también una extensión del disfraz simbólico formal hacia todas aquellas conductas consideradas como propias de la labor policial. Esto quiere decir que los agentes y mandos de la policía judicial, en gran parte de sus interacciones cotidianas, representan papeles según los cometidos formales asignados por reglamentos, autoridades y políticas de gobierno. Este esfuerzo permanente les permite construir un entorno simbólico donde sus conductas puedan ser interpretadas en coherencia con estos fines.

La distancia que existe normalmente entre lo prescrito, lo reglamentado o lo ordenado, y las condiciones y restricciones reales con las cuales los policías trabajan, tiene como consecuencia una inflación de papeles cuya finalidad es lograr una mínima coherencia estructural que permita la reproducción institucional y de los nichos laborales que ocupan sus funcionarios. Esta constante creación de perífrasis conductuales para expresar rasgos formalmente atribuidos y asignados convierte a los policías en investigadores de papel, según la propia fórmula de un agente veterano: "una investigación requiere tiempo, pero ahora sólo somos investigadores de papel, es decir, 


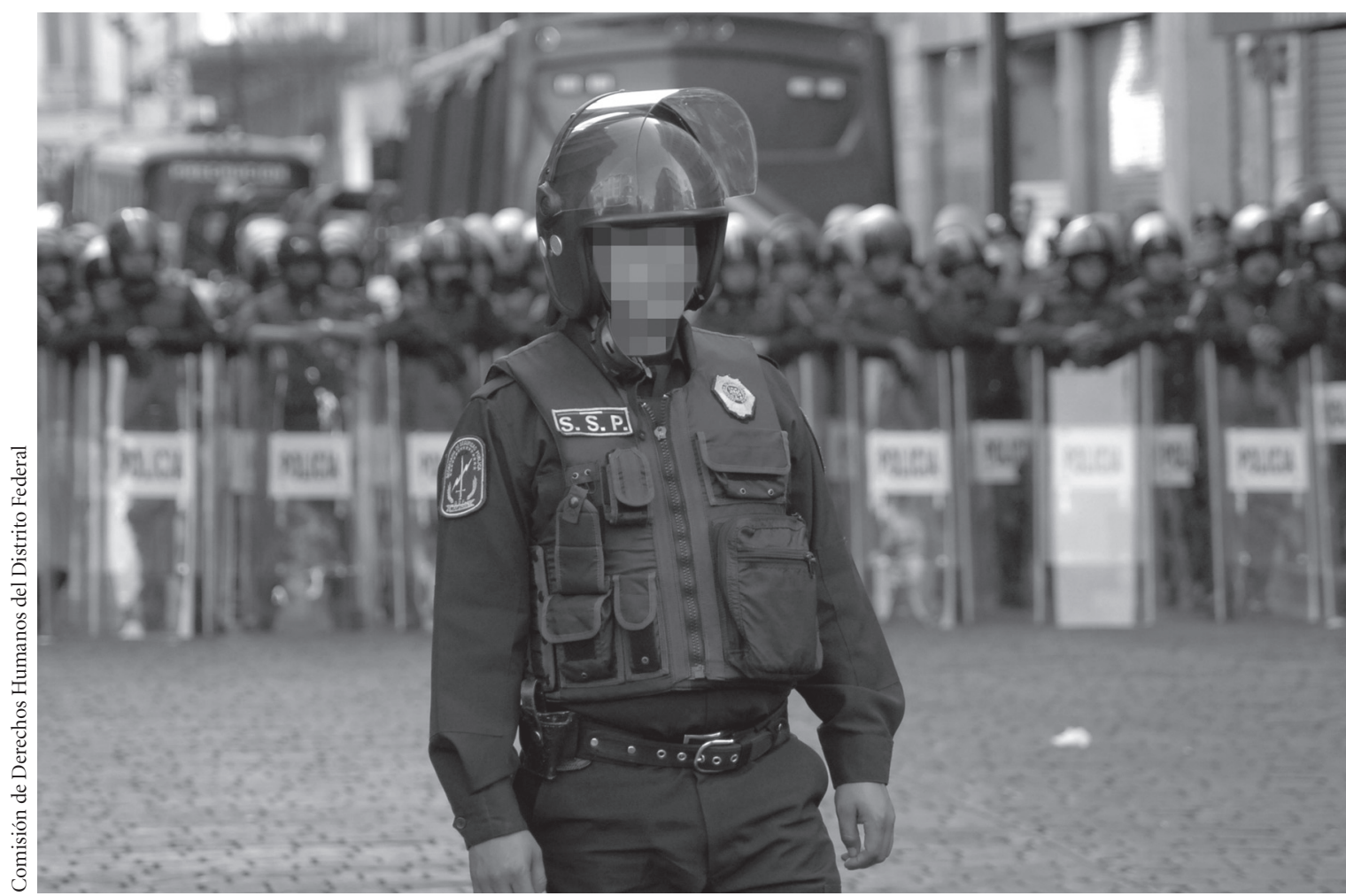

Bloqueo policiaco en una vialidad, 2009.

a base de puros informes y de mentiras se lleva a cabo todo" (GD 07). Esto se ha de entender tanto en la acepción literal de cumplimentar impresos e informes que serán elaborados y presentados para simular la realidad de lo investigado y del trabajo hecho, como también en el sentido de la representación de un papel o rol de acuerdo con la función policial formal. Ambos sentidos, lo simulado y lo teatral, le proporcionan a la labor policial su carácter escénico o ficticio.

Son numerosos los ejemplos, develados por los policías en los grupos de discusión, de cómo gran parte de sus energías se invierten en un constante hacer "como si", en escenificar un trabajo para cumplir aparentemente con los objetivos marcados o las órdenes recibidas, básicamente a través de la elaboración de informes ficticios. Un agente se queja de que: "difícilmente se trabajan investigaciones, entonces nomás metemos pura paja, uno mete reportes que no son reales" (GD 10).
Estos artificios y estratagemas aparecen en todos los grados y generaciones, y son del común dominio dentro de la cultura policial, por lo que se deduce de ello que tales papeles no son adoptados principalmente con el fin de engañar a alguien, sino de simular, por lo menos al interior de la propia institución. Se trata de representaciones en las que la mayoría de los participantes conoce la condición "escénica" de las conductas, pero en las que, al mismo tiempo, todos están de acuerdo en otorgarse mutuamente verosimilitud a nivel formal. Es éste otro de los rasgos de las prácticas paralegales y las conductas corruptas: el intercambio de papeles en reciprocidad con la anuencia de ambas partes. Un agente expresa de la siguiente manera esta complicidad: "cada quien tenemos mucho trabajo y por eso informamos pura basura: que fui, que no lo encontré, que no vive ahí" (GD 10).

Como es de imaginar, el mero hábito de llenar los oficios simulando haber llevado a cabo investigaciones, o 


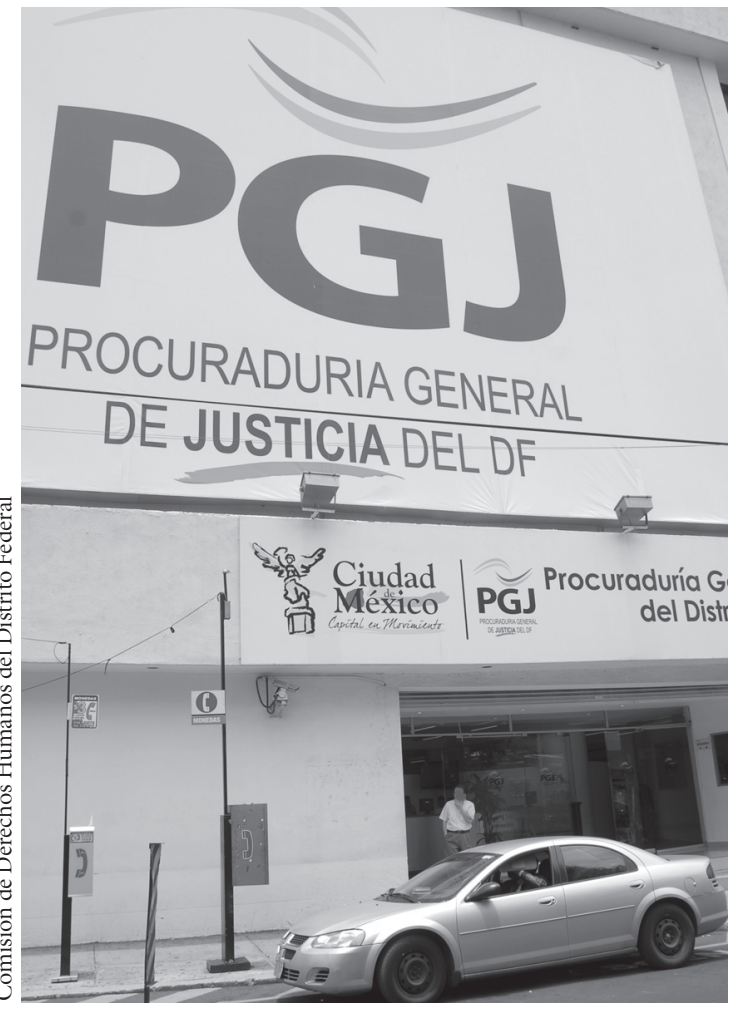

Centro de operaciones, 2008.

puestas a disposición jurídicamente fundamentadas, es un factor que redunda en una multiplicación de los efectos paralizantes que recaen sobre la institución. Así, a medida que las suplantaciones van teniendo éxito, éstas se convierten en modelos a seguir dentro de los clanes mediante el aprendizaje vicario, por lo que se produce una reacción inflacionaria: cada vez son necesarios más informes ficticios, más tiempo para elaborarlos y nuevas estrategias de presentación para asegurar un nivel equivalente de reproducción institucional, con el agravante de que aumenta, si cabe, la desconfianza de la ciudadanía hacia la Procuraduría.

Una característica notable de la escenificación y la simulación es la facilidad y rapidez con que son adoptadas por los nuevos policías. Éste es un síntoma claro de reproducción intergeneracional de las prácticas corruptas, y que relativiza las numerosas declaraciones sobre conflictos entre novatos y veteranos. Una agente nos explica:
"Uno hace tarjetas informativas, las sellas y las guardas, y con eso ya te evitas problemas. En el Instituto no les informan nada de esto a los alumnos, ni les enseñan cómo hacer tarjetas informativas" (GD 13).

La proliferación de informes simulados en el contexto intrainstitucional también tiene su correlato en las estadísticas que la Procuraduría rinde ante las autoridades políticas y los medios de comunicación. Este otro conjunto de prácticas de simulación — que en realidad no son más que la consecuencia y la extensión de los informes ficticios de los agentes- lo constituyen aquellos reportes oficiales que son maquillados para enmascarar los datos reales ante la administración y la opinión pública, relativos a índices delictivos y de aprehensión de delincuentes. Son numerosos los elementos y mandos entrevistados que nos han confirmado la existencia de esta práctica de enmascaramiento de la información. Un agente lo explica recurriendo también a la metáfora del papel: "se quiere hacer sólo una policía de papel. A mí me da vergüenza que el Procurador salga en la tele y diga que agarramos a tal y tal, y no puede decirlo porque hace tiempo que no agarramos a nadie relevante, a nadie" (GD 11). De nuevo aquí las escenificaciones parecen llevarse a cabo con el conocimiento de todas la partes (elementos, mandos, cargos políticos, medios de comunicación, opinión pública) de que se trata de datos simulados, presentados para hacer cuadrar la función institucional supuestamente real con el cometido formal de la procuración de justicia.

Por la información que hemos obtenido en los Grupos de Discusión, parece ser que las estrategias de simulación son diversas, ocurren simultáneamente y solapadas unas con otras. Esto significa que para un mismo conjunto de eventos (delitos, puestas a disposición, etc.) puede haber diversas prácticas enmascaradoras, que actúan al mismo tiempo y según se asciende en la cadena de mando. Hay que remarcar que este fenómeno podría tener un efecto acumulador de las simulaciones que se dan en los diversos niveles jerárquicos, produciendo maquillajes de datos que, a su vez, ya han sido alterados o incluso inventados.

Pero, entonces, si todos o la mayoría de los participantes en los intercambios son conocedores de la escenificación y la simulación, ¿para quién y para qué se representan los papeles? Nosotros creemos que los papeles se inter- 
pretan principalmente para la propia institución, aunque también puede ser que ante ciertos cargos políticos; su finalidad, como ya hemos dicho, es la reproducción institucional. ¿Qué significa esto? Pues que, aunque suene paradójico, la propia institución genera sus propias trampas: reglas, normas y objetivos inalcanzables que deben ser cumplidos y para cuyos efectos se despliega todo un entramado escénico en el que los diversos participantes quedan atrapados en sus propias coartadas a medida que se ponen a circular. Una vez que el teatro está en funcionamiento nadie puede o se atreve a marcar la distancia suficiente para objetivar su propio trabajo y cuestionar los roles. Se pondría en peligro, con ello, la estabilidad de los nichos laborales.

\section{CONCLUSIONES}

Si bien los eufemismos legales que usan los policías judiciales proveen de coartadas para la legitimación de la violencia institucional, esta violencia no ha nacido de sujetos concretos que echan mano de ella en un repertorio de recursos, sino que deriva de la propia fuerza coercitiva y punitiva que el Estado se otorga a sí mismo. Ya hemos visto cómo una estrategia de dominación puede redoblar su eficacia si apela al lenguaje eufemístico que encubre el horror de la violencia, por lo que podemos deducir que todo el complejo institucional del Estado, basado en el burocratismo y el fetichismo del documento escrito, no sería sino una enorme escenificación para no tener que decir lo que en realidad es: una estructura de dominación enraizada por medio de la violencia y el miedo. Siguiendo este argumento podríamos llegar a afirmar que las prácticas de abuso de poder y de corrupción que llevan a cabo buena parte de los policías judiciales no son sino una aplicación arbitraria y particularista (perversa) de esa máxima que predica la igualdad de todos los ciudadanos frente al monopolio del ejercicio de la violencia del Estado; es decir, la ley. En consecuencia, los servidores públicos de la procuración de justicia, en vez de hacer de esta máxima un precepto universal, disgregarían la legitimidad del Estado en violencias locales e interesadas, parciales, mediante la puesta en práctica de toda una "micropolítica entre parti-

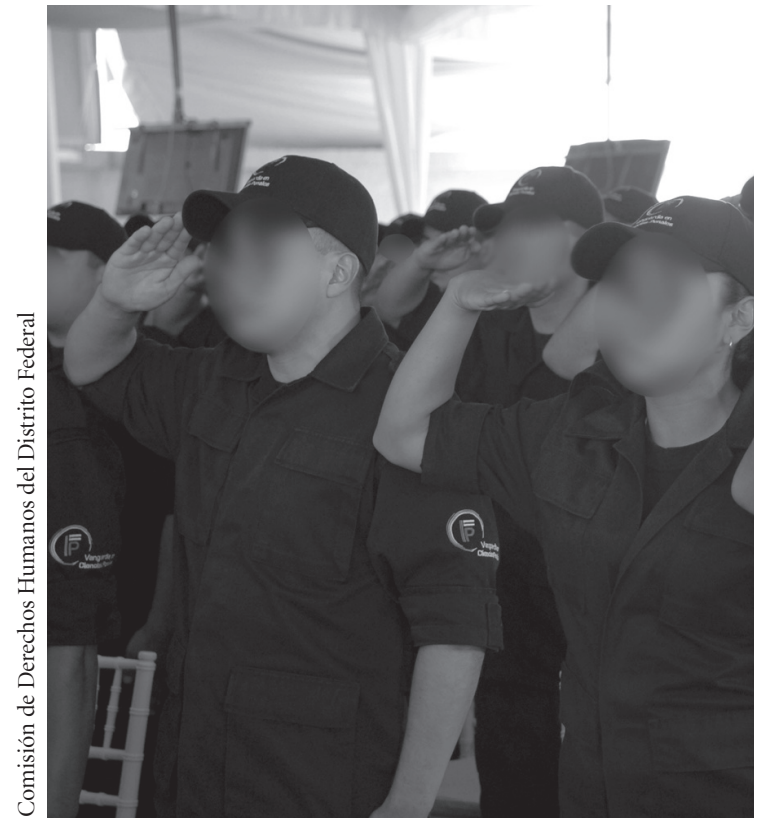

Entrenamiento, 2009.

culares", sesgada e injusta, pero eficaz para obtener recursos y un entorno más seguro. Las prácticas de abuso de poder y de corrupción aparecen como funcionales en estos niveles infinitesimales, y contribuyen paradójicamente a la reproducción institucional. Pero son también prácticas ejecutadas en un campo de poder enormemente inestable y cruzado de conflictos de toda naturaleza: de clase, generacionales, jerárquicos, ideológicos, entre otros. Por eso causan tanta disrupción y rechazo entre la sociedad.

Pero, ¿por qué decimos que los policías judiciales son investigadores de papel? Hemos llegado a esta conclusión por los siguientes motivos:

a) Porque los policías judiciales representan un papel como si actuaran con apego a la legalidad y realizaran operativos eficientes contra la delincuencia. Actúan el papel de policías mediante unas dramatizaciones que ellos preparan para poder hacerse pasar por o hacer como si... y asegurar, de esta manera su nicho laboral y la obtención de recursos mediante el abuso de poder.

b) Porque los policías judiciales realizan reportes de investigaciones nunca llevadas a cabo y basan la apariencia 


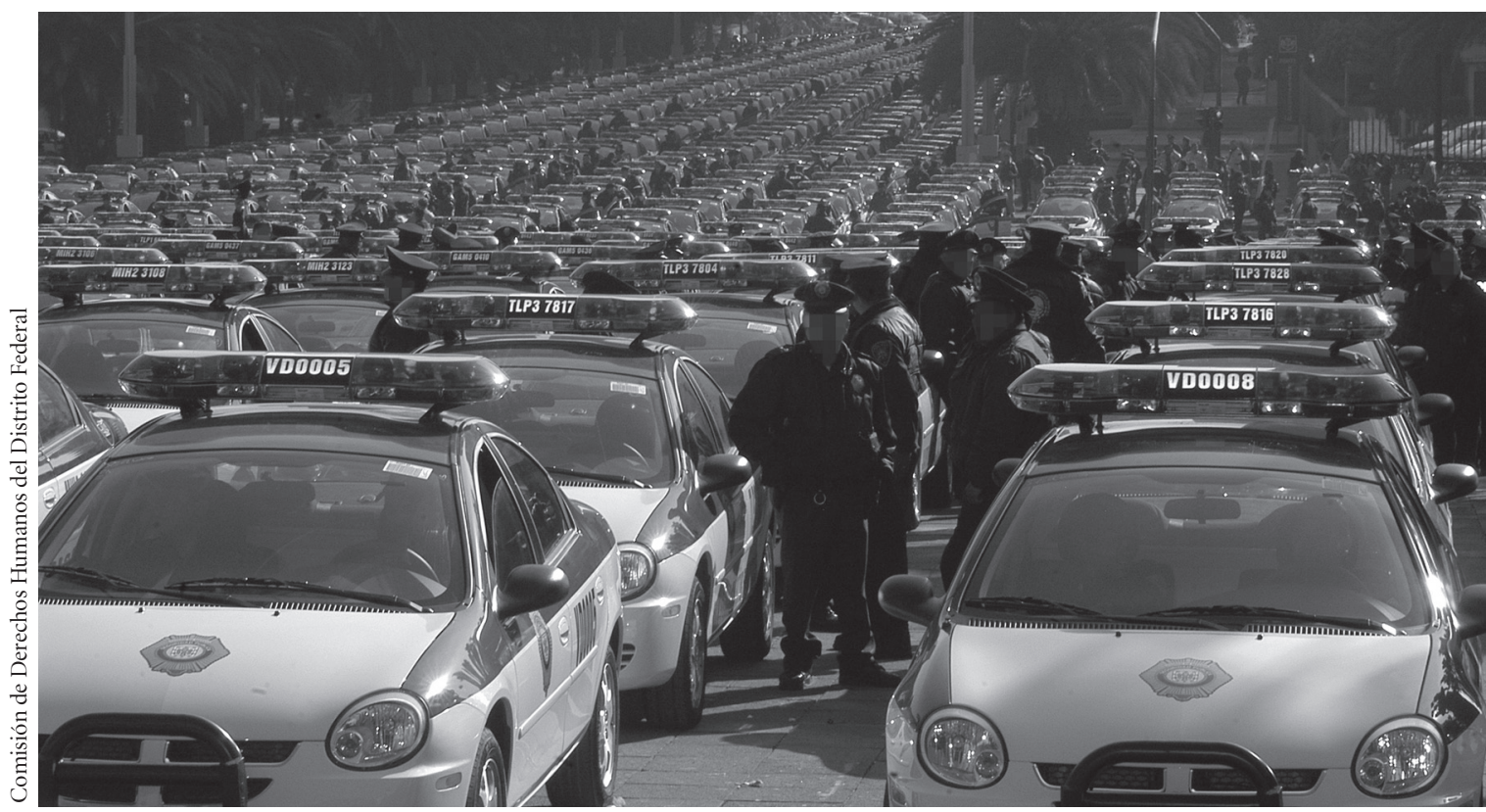

El acceso a los recursos es fuente de tensión al interior de los cuerpos policiacos, 2005.

Los policías viven la cultura del simulacro y se aprovechan de la burocratización extrema de la máquina estatal. Pero bajo el papel escrito está la corrupción, la alteración de los datos para beneficio personal y corporativo. La realidad se adapta a los papeles e informes, y las personas también.

c) Porque los policías judiciales utilizan las leyes, lo oficial, lo escrito, como coartada para el ejercicio del poder arbitrario. El papel legal se eleva en símbolo de este poder, y la extorsión y el abuso sólo son posibles si existe el papel de la ley.

La institución de procuración de justicia en el Distrito Federal está socavada por procesos, tanto de índole interna como externa, que debilitan el precario equilibrio entre el orden institucional que procura su reproducción, y las fuerzas disgregadoras que tienden a su volatilización en regímenes locales. Éstos son los más importantes:

1) Los órganos existentes de control interno contienen mecanismos perversos que generan más corrupción, debido principalmente a que sus miembros pertenecen a los mismos clanes que los funcionarios cuyas prácticas han de ser controladas. Además, los índices mínimos de productividad exigidos a los policías y que se traducen en "puestas a disposición" son causa directa de las arbitrariedades en la detención en falsa flagrancia de individuos criminalizables, en la creación de pruebas falsas o en el sembrar evidencias, y en la confesión forzada. La mayor parte de los mecanismos creados y ejecutados para prevenir y erradicar la corrupción generan más corrupción y abuso de poder, ya que acaban por convertirse en coartadas para justificar y legitimar estas prácticas y en argumentos de autoexculpación de los policías.

2) Los miembros de la policía judicial actúan principalmente en defensa de los intereses de aquellos que pertenecen a sus propios clanes, alrededor de los cuales se perfilan las obligaciones morales de sus miembros para facultar la supervivencia (laboral, pero también física). La lealtad a la institución es expresada en el plano ideológico como alta, sobre todo por parte de los mandos, pero la fidelidad se dirige principalmente hacia el 
entorno socio-laboral más cercano, con el fin de crear relaciones de confianza y protección mutua. En el nivel más pragmático, la solidaridad se orienta hacia el clan en el cual se desarrolla la estrategia de supervivencia.

3) La corrupción existe en todas las relaciones sociales que establecen los policías judiciales (lo cual no significa que todos actúen de forma corrupta). Sólo varía la función jerárquica y desigualitaria; es decir, el aspecto cualitativo de la relación. Así, dentro de los clanes, las prácticas de corrupción se establecen como dones entre iguales aliados (inversión en capital simbólico) y entre clanes policiales, o entre éstos y otros pertenecientes a la Procuraduría, en los que predominan las reciprocidades interesadas entre iguales y jerárquicos competitivos (inversión en capital de poder). Al contrario, entre un clan policial y los superiores jerárquicos, o entre un clan y la sociedad civil, las prácticas de corrupción existentes son abusos de poder.

4) La profesionalización de la formación policial ha generado un debilitamiento de la capacidad de reproducción intergeneracional del corpus moral, debido principalmente a las nuevas ideologías legalistas que han penetrado en la institución. Pero tal debilitamiento no conduce necesariamente a una reducción de la corrupción, sino a la irrupción de nuevos ethos de conducta policial que incluyen una deslegitimación de la jerarquía basada en la experiencia y un aumento del prestigio fundado en la meritocracia. Se trata de luchas de poder internas que es probable que se resuelvan con la irrupción de un nuevo modus operandi de la reproducción institucional, basado en otros valores ideológicos usados como coartada de dominación.

5) El fracaso del sistema jurídico-penal y de la institución policial puede resultar eficaz políticamente hablando, ya que contribuye al control de la población, aunque sea a costa de una dilapidación de los valores democráticos. No obstante, una mayor eficacia policial no se contrapone a los valores de legalidad y debido proceso, sino que deben ser sus fundadores. Las argumentaciones a favor del privilegio de la discrecionalidad y excepcionalidad por parte de los policías no son llamados a aumentar la eficacia de la institución según las reglas formales que regulan la fuerza del Estado, sino a incre- mentar la violencia institucional para acrecentar la eficacia en el proceso de "selección" de delincuentes para el sistema carcelario.

6) Existe un umbral de tolerancia de las prácticas corruptas y de la disfunción institucional pasado el cual éstas se convierten en amenazantes para el modelo del Estado sustentado por el sistema carcelario, y para sus sectores sociales beneficiarios, ya que podría colapsarse el sistema. La defensa de los derechos humanos, mediante su uso neopunitivista, está siendo instrumentalizada en ciertos casos con el cometido de mantener la violencia institucional por debajo de este umbral. Esto se lleva a cabo gracias a un proceso de autocastigo institucional dirigido a una selección de policías que sirven de chivos expiatorios, normalmente agentes de baja graduación en situaciones de desamparo por parte de sus jefes o iguales, o personajes satélite marginales o novatos en los clanes. Se trata de una caza de brujas simbólica que poco modifica la conducta de la mayoría de los policías. Al contrario, parece exacerbar todavía más las prácticas de abuso de poder dado que a estos policías tampoco se les respetan sus derechos como acusados en los procedimientos penales que enfrentan. Así, el sistema jurídico-penal se convierte en un arma de violencia institucional de unos contra otros, pero siempre dirigida a los miembros más desfavorecidos.

Finalmente, hay que remarcar que los derechos humanos también deben ser ejercidos y exigidos dentro de unos límites, si realmente han de ser eficaces para prevenir y combatir la violación de los bienes fundamentales de los ciudadanos que se enfrentan al Estado.

\section{Bibliografía}

Amnistía Internacional, 2004, Memorándum al Congreso de la Unión sobre las reformas de la Constitución y del sistema de justicia penal, México. En línea: <http://web.amnesty.org/ library/Index/ESLAMR410322004>.

Azaola, Elena, 2006, Imagen y autoimagen de la policía de la ciudad de México, Ediciones Coyoacán, Foro Latinoamericano para la Seguridad Urbana y la Democracia, Centro de 
Investigaciones y Estudios Superiores en Antropología Social, Secretaría de Seguridad Pública, México.

Beristáin, Helena, 2001, Diccionario de retórica y poética, Miguel Ángel Porrúa, México.

Buckner, Taylor, Nils Christie y Ezzat Fatth, 1983, "Policía y cultura”, en José María Rico (comp.), Policía y sociedad democrática, Alianza Editorial, Madrid.

Cohen, Abner, 1974, Two-Dimensional Man: An Essay on the Anthropology of Power and Symbolism in Complex Society, Routledge \& Kegan Paul, Londres.

Comisión de Derechos Humanos del Distrito Federal, 2005, Informe estadístico anual 2004 de la Dirección de Quejas y Orientación. En línea: <http://www.cdhdf.org.mx/ index. php?id=queyo0104>.

_ 2006, Informe estadístico anual 2005 de la Dirección de Quejas y Orientación. En línea: <http://www.cdhdf.org.mx/ informes/quejas/quejas06.pps>.

__ 2007a, Informe estadístico anual 2006 de la Dirección de Quejas y Orientación. En línea: <http://www.cdhdf.org.mx/ informes/quejas/2007/01estadistico2006.pdf $>$.

__, 2007b, Recomendación 10/2007. En línea: <http://www. cdhdf.org.mx/index.php?id=reco1007>.
Davis, Diane E., 2006, "Undermining the Rule of Law: Democratization and the Dark Side of Police Reform in Mexico", Latin American Politics and Society, vol. 48, núm. 1, primavera, pp. 56-86.

Gadamer, Hans-Georg, 2005, Verdad y método, Ediciones Sígueme, Salamanca.

Goffman, Erving, 1993, Estigma. La identidad deteriorada, Amorrortu, Buenos Aires.

Matza, David, 1981, El proceso de desviación, Taurus, Madrid.

Méndez, Juan E., 2002, "Problemas de violencia ilegal”, en Juan E. Méndez, Guillermo O’Donnell y Paulo Sérgio Pinheiro (comp.), La (in)efectividad de la ley y la exclusión en América Latina, Paidós, Buenos Aires.

Naval, Claire, 2006, Irregularidades, abuso de poder y maltratos en el Distrito Federal. La relación de los agentes policías y del Ministerio Público con la población, Fundar, Centro de Análisis e Investigación, México.

Pastor, Daniel R., 2005, "La deriva neopunitivista de organismos y activistas como causa del desprestigio actual de los derechos humanos", Nueva Doctrina Penal, núm. 1, pp. 73-114. 